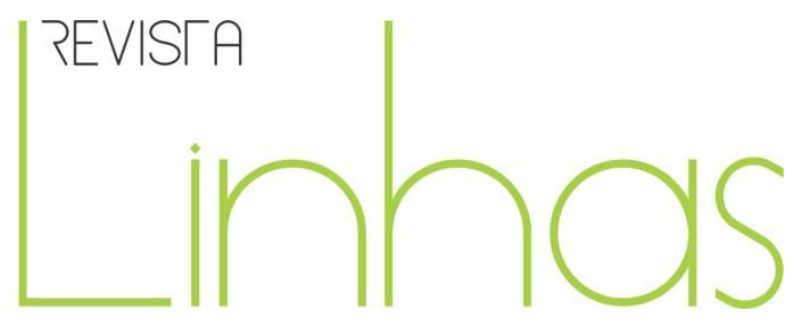

\title{
Jogos analógicos e digitais na escola: uma análise comparativa da atenção, interação social e diversão
}

\begin{abstract}
Resumo
Os jogos são reconhecidos por seu potencial educativo e apresentam-se sob diferentes modalidades e formatos. Diante disso, este artigo tem como objetivo analisar as diferenças decorrentes do uso de jogos analógicos e digitais no contexto escolar, enfatizando os comportamentos sociais manifestos durante a realização das atividades com diferentes tipos de jogos. Participaram da pesquisa 25 estudantes do terceiro ano dos Anos Iniciais de uma escola pública federal, com idades entre oito e nove anos. Foram realizadas quatro intervenções que foram observadas com base nos procedimentos da descrição narrativa e do registro da frequência por amostragem de tempo com o uso de dois jogos, sendo um deles o Material Dourado, na versão analógica, e o Blocos no formato digital; o outro jogo é o Tangram, também proposto em ambas versões, aplicados cada jogo e versão em momentos distintos. A partir dessa proposição, a análise pautou-se nas categorias da atenção, interação social e diversão presentes durante o uso do jogo com as crianças. Os resultados revelaram que se tem uma frequência maior de comportamentos que indicam diversão na interação com o jogo digital, havendo menor dispersão com essa versão. Já no jogo analógico, identificou-se maior interação entre as crianças na prestação de auxílio aos colegas e menor necessidade de mediação da professora. Com isso, conclui-se que o tipo de experiência e comportamentos manifestos na interação com os jogos não dependem apenas do formato, digital ou analógico, mas também das características do jogo e das possibilidades de interação no espaço.
\end{abstract}

Palavras-chave: Jogos analógicos. Jogos eletrônicos. Interação social.

\section{Daniela Karine Ramos}

Universidade Federal de Santa

Catarina - UFSC - Florianópolis/SC Brasil

dadaniela@gmail.com

Ana Paula Knaul

Universidade Federal de Santa Catarina - UFSC - Florianópolis/SC Brasil

anaknaul@gmail.com

\section{Aline Rocha}

Universidade Federal de Santa Catarina - UFSC - Florianópolis/SC Brasil alirocha@gmail.com

\section{Para citar este artigo:}

RAMOS, Daniela Karine; KNAUL, Ana Paula; ROCHA, Aline. Jogos analógicos e digitais na escola: uma análise comparativa da atenção, interação social e diversão. Revista Linhas. Florianópolis, v. 21, n. 47, p. 328-354, set./dez. 2020. 


\title{
Analog and digital games at school: a comparative analysis of attention, social interaction and fun
}

\begin{abstract}
The games are recognized for their educational potential and present themselves on different modalities and formats. Therefore, this article aims to analyze the differences between analog and digital games in the school context, emphasizing the social behaviors manifested during the performance of activities with different types of games. The study included 25 students of a federal public school, aged between 8 and 9 years. Four interventions were performed that were observed based on the procedures of the narrative description and the recording of frequency by time sampling using two sets, one of them being the Gold Material in the analog version and the Blocos in the digital format and the other the Tangram, also proposed in both versions, applied each game and version at different times. From this proposition the analysis was based on the categories of attention, social interaction and fun present during the use of the game with the children. The results revealed that there is a greater frequency of behaviors that indicate fun in the interaction with the digital game, being less dispersion with this version. Already in the analog game, it was identified a greater interaction between the children in the provision of help to the colleagues and less need of mediation of the teacher. Thus, it is concluded that the type of experience and manifest behaviors in the interaction with games depend not only on digital or analog format, but also on the characteristics of the game and the possibilities of interaction in space.
\end{abstract}

Keywords: Games. Digital games. Social interaction. 
Conceituar jogo é uma tarefa difícil porque inclui uma diversidade de tipos e categorias, relacionando-se fortemente com a cultura e os contextos históricos em que se manifestam. Para Huizinga (2010), o jogo está intimamente atrelado à cultura da humanidade e configura-se como resultado dos contextos históricos que acompanham o ser humano ao longo do tempo. O jogo é lúdico, fictício, fora da vida real, transcendendo as obrigações cotidianas, e caracteriza-se por ser uma atividade livre, "não séria" permeada por prazer e tensão, pois ao mesmo tempo em que o jogador têm o prazer de jogar, também é posto sob a tensão provocada pela competição, pela busca da vitória e pelo respeito às regras (HUIZINGA, 2010).

Na tentativa de compreender os jogos, Caillois (1990) realiza uma classificação em categorias: Agôn (jogos de competição), Alea (jogos de sorte), Mimicry (jogos simbólicos ou de imaginação) e Ilinx (jogos de risco ou desafio). Apesar de propor essa organização, o autor reconhece que ela não contempla todos os tipos de jogos, por se tratar de um amplo e diverso universo de possibilidades.

Muitos outros teóricos e pesquisadores têm procurado definir e compreender os jogos, como Kishimoto (1999) que sistematiza três aspectos de diferenciação dos jogos. O primeiro trata o jogo como sistema linguístico que está inserido em um contexto social, ou seja, o jogo funciona como expressão linguística pragmática utilizada como forma de expressão de valores e modo de vida. No segundo aspecto, a autora descreve o jogo como sistema de regras, destacando que cada um possui estruturas sequenciais de regras que os diferenciam, "permitindo superposição com a situação lúdica, ou seja, quando alguém joga, está executando as regras do jogo e, ao mesmo tempo, desenvolvendo uma atividade lúdica" (KISHIMOTO, 1999, p. 17). O terceiro aspecto descreve o jogo como um objeto, que se materializa por meio das peças, tabuleiros ou cartas, que podem ser confeccionadas com diferentes materiais, respeitando suas características, funções e objetivos.

No contexto contemporâneo, o desenvolvimento tecnológico conjecturou para o surgimento dos jogos digitais que ampliam ainda mais a complexidade e as inúmeras possibilidades dos jogos se darem como experiências humanas, sociais e historicamente 
constituídas. Os jogos digitais se diferenciam dos analógicos por apresentarem uma interface lúdica, que regula e orienta suas regras, ações e decisões por meio de recursos computacionais (SCHUYTEMA 2008).

Diante do potencial que os jogos podem oferecer aos processos de ensino e aprendizagem, este estudo tem como objetivo analisar as diferenças decorrentes do uso de jogos analógicos e digitais no contexto escolar, enfatizando os comportamentos sociais manifestos durante a realização das atividades com os diferentes tipos de jogos.

\section{Jogos analógicos e digitais: características e contribuições}

Ao se comparar um jogo analógico ao jogo no ambiente virtual, percebe-se que algumas características continuam inalteradas pela sua essência, como ser regido por um conjunto de regras. Mas o jogo digital tem como diferencial principal a construção visual e a interatividade, ou seja, o jogo físico contém peças e objetos palpáveis, enquanto o digital utiliza esses elementos representados por meio de gráficos interativos, visualizados pelo jogador no monitor ou tela.

A partir dessa diferenciação entre jogos digitais e analógicos, Juul (2003) chama atenção para algumas características que podem ser observadas entre eles, a qual a primeira ressaltada pelo autor versa sobre o ambiente fictício onde acontece o jogo. No jogo digital, a imersão e interação levam o jogador a envolver-se por meio dos aspectos lúdicos em um mundo abstrato e virtual (JULL, 2003). Já nos analógicos, segundo o autor, esse mundo fictício também pode ser criado no imaginário de cada jogador, mas com a diferença de que essa representação é realizada em um mundo singular, que não pode ser compartilhado concretamente.

Outra característica ressaltada por Juul (2003) é a forma como são estabelecidas as regras e como elas são colocadas em prática no jogo. Nos digitais, as normas que compõe o jogo são determinadas por meio de programação computacional, tornando inviável alterar ou negociar as regras estabelecidas ou as consequências pelo não cumprimento delas, sem alterar a programação feita pelo sistema. Já nos jogos analógicos, tanto as normas estabelecidas pelos jogadores como as consequências pelo não cumprimento dos combinados podem sofrer transformações, se os jogadores assim 
acordarem, ou seja, os jogos analógicos contam com uma maior flexibilidade que os jogos digitais.

Nesse sentido, pode-se concluir que independentemente do tipo de jogo as regras fazem parte desse universo e de certa forma são elas que motivam os jogadores a ultrapassar seus limites a partir das limitações impostas por elas (HUIZINGA, 2010).

Apesar da motivação, dos aspectos da interação social e do lúdico associados ao jogo, este nem sempre foi reconhecido como uma experiência potencialmente educativa, de acordo com Brougère (1998). Antes de se estabelecer uma relação entre o jogo e a educação, este era considerado sob as perspectivas de recreação, de observação escolar ou atividades físicas. Na primeira perspectiva, o jogo era visto como relaxamento entre os momentos de trabalho ou estudo. Na segunda, era um instrumento de observação, em que os professores o utilizavam para observar as aptidões e habilidades das crianças. “Aqui o jogo não é formador, mas revelador” (BROUGÈRE, 1998, p. 57). Essa perspectiva ainda mantém o jogo à margem das atividades educativas, mas, ao mesmo tempo, lhe dá um lugar de destaque que mais tarde possibilitará um novo olhar pedagógico sobre ele. Na terceira perspectiva, o jogo é visto como suporte para que as atividades físicas se desenvolvam sem a preocupação com as características ou tipos de jogos.

A partir de teóricos como Montessori, Decroly e Freinet, o jogo passa a ter um papel de destaque na educação das crianças no contexto escolar, e Kishimoto (2002) explica que o significado atual e o objetivo dos jogos educativos é o equilíbrio entre a união da necessidade de brincar da criança com os objetivos pedagógicos do educador. Nesse sentido, o jogo educativo assume duas funções: a lúdica e a educativa. A autora explica que a função lúdica é aquela que proporciona diversão, o prazer e a tensão provocada pelo jogo; a função educativa é aquela que ensina, instrui, completa o saber e o conhecimento da criança.

O jogo, no contexto escolar, pode ser um importante instrumento de interação, de experimentação e de construção de conhecimentos, utilizando o potencial lúdico para o desenvolvimento e o exercício de novas estrutura cognitivas, pois coloca os estudantes diante de desafios que os aproximam de conteúdos e habilidades que devem ser conquistadas no ambiente escolar (KISHIMOTO, 1999). O jogo "é um elemento 
transmissor e dinamizador de costumes e condutas sociais. Pode ser um elemento essencial para preparar de maneira integral os jovens para a vida" (MURCIA, 2005, p. 11).

De maneira mais específica, os jogos digitais proporcionam resultados positivos na aprendizagem, levando os estudantes a ficarem mais motivados, melhorando seu empenho e rendimento escolar (TELEB et al., 2015). Também foi constatado em pesquisas que com os jogos digitais, quando utilizados para o desenvolvimento de atividades de resolução de problemas, principalmente na disciplina de Matemática, os estudantes têm maior facilidade para identificar informações importantes, planejar estratégias, apontar soluções criativas, sendo uma alternativa para o exercício do raciocínio lógico (CUNSKAA; SAVICKAA, 2012; GARCIA; PACHECO 2013; MAHMOUDI et al., 2014).

Os jogos digitais podem fazer uso de aspectos ficcionais para criar uma realidade virtual, na qual o jogador exerce um papel e uma função de acordo com as regras estabelecidas. A combinação dos recursos digitais interativos possibilita a reprodução do real utilizando cores, imagens e movimentos e muitas vezes, segundo Mrech (1997), nos informam sobre o mundo, o refazem, transformando-o num espetáculo que permite recriar (interagir) com parte desta realidade virtual. Assim, pode-se ter a imersão dos jogadores em situações de risco e perigo, nas quais é possível experimentar sensações e situações de ameaça física e psicológica sem correr esses riscos na vida real, o que já não é possível realizar em jogos analógicos, caso os jogadores tentassem simular qualquer uma das situações citadas, pois poderiam correr ameaça real.

As experiências vivenciadas na interação com os jogos digitais constituem-se como fontes de aprendizagem, por envolverem ações contextualizadas em narrativas, a tomada de decisões, a experimentação, o exercício de habilidades e a reflexão sobre as ações. Diante disso, Schell (2011) expõe que tudo que se sente é real, pois a realidade é a interpretação das experiências que as pessoas vivem, ou seja, a mente filtra por meio dos sentidos a realidade, a interpreta e a projeta para experiências vividas. Isso acontece no mundo dos jogos, que mesmo não sendo o mundo concreto, proporciona experiências que se tornam repertório para outras situações da vida real.

Nesse sentido, Gee (2009), ressalta que as características existentes nos jogos digitais podem propiciar aprendizagem significativa para os estudantes, pois "o desafio e a aprendizagem são em grande parte aquilo que torna os videogames motivadores e 
divertidos" (GEE, 2009, p. 168). Ao mesmo tempo em que os jogos digitais, no contexto educacional, proporcionam aos estudantes um melhor desempenho das habilidades cognitivas, pois possuem características como a imersão, o feedback imediato e os desafios que os tornam prazerosos e motivadores para os estudantes (MARTINOVIC, 2016; UCUS, 2015).

Diante disso, ressalta-se que muitas pesquisas indicam que o uso dos jogos digitais na educação traze benefícios ao processo de ensino e de aprendizagem, sendo uma possibilidade a ser explorada como instrumento inovador na metodologia de ensino (CONNOLLY, 2012; LI; TSAI, 2013). Martinovic et al. (2016) constata que com o uso de jogos digitais, os estudantes tiveram um maior engajamento nas atividades propostas e que, consequentemente, trouxeram melhor desempenho nos jogos utilizados durante a pesquisa.

Na comparação entre os jogos digitais e analógicos, Santos, Silva e Silva Junior (2014) constatam que a virtualização de jogos tradicionais pode trazer benefícios ao processo de ensino e aprendizagem da matemática, no entanto, apontam que é necessário o desenvolvimento de mais pesquisas nessa área.

Outro aspecto fortemente exercitado com os jogos é a interação social. Nos analógicos, ela revela-se na combinação das regras, definição de papéis, nos diálogos e desenvolvimento dos jogos quando acontecem no coletivo. Já nos digitais, podemos ter a interação mediada que ocorre em jogos coletivos on-line, que dispõem de ferramentas de comunicação. Além disso, temos o uso dos jogos digitais em espaço coletivos como na escola ou na interação entre duas ou mais criança com um dispositivo que possibilita o acesso ao jogo digital.

Diante disso, percebe-se que a interação social também é um fator importante no uso dos jogos digitais. Pensando sobre as habilidades sociais que se constituem a partir das relações sociais estabelecidas, numa pesquisa realizada por Mona Sakr e Natalia Kucirkova (2017), as autoras buscaram analisar possibilidades de aproximar a relação entre pai e filho de três anos de idade no uso de diferentes tecnologias digitais e não digitais como colagem, giz de cera, aplicativo de iPad e o software Tuxpaint no laptop. A partir disso, elas identificaram que não foi a diferença da tecnologia ser digital ou não que interferiu no nível de interação entre o pai e a criança, mas foram as potencialidades do 
que os recursos podiam fazer fisicamente e como cada atividade era percebida e dominada pelos dois, que determinaram uma maior ou menor proximidade entre ambos durante o uso.

Para seguir na reflexão sobre a qualidade das interações sociais mediante o uso da tecnologia digital, na pesquisa realizada por Michael Tscholl e Robb Lindgren (2014) foi analisado o uso de uma tecnologia projetada para promover a aprendizagem por meio da interação das crianças com as suas famílias no uso da tecnologia digital em um museu. Nessa proposta, havia um simulador de realidade aumentada que exigia que as crianças acertassem um alvo localizado atrás de um planeta para identificar a compreensão sobre gravidade na duplicação da velocidade de um asteroide, enquanto as famílias tinham acesso a outros conteúdos para questionar as crianças a respeito da atividade realizada na simulação. Concluiu-se nessa pesquisa que a aprendizagem se deu na interação, entre crianças e famílias e pela motivação proporcionada pelo simulador.

Na pesquisa realizada por Reynolds-Blankenship (2013), o uso do Ipad de forma livre, foi integrado nas práticas de ensino e aprendizagem de um jardim de infância para apoiar a alfabetização digital e motivar interações. Concluiu-se que o jogo digital utilizado, possibilitou que as crianças estabelecessem suas interações sociais entre grupos, controlando os conflitos nas relações e colaborando umas com as outras.

De igual modo, Knaul (2015), em sua pesquisa, analisou as contribuições da integração do tablet às práticas pedagógicas nos Anos Iniciais. Teve como resultado que a tecnologia digital atrelada ao conteúdo utilizado, somados às estratégias pedagógicas planejadas para esse acesso, motivam práticas de colaboração diversas entre as crianças, desenvolvendo, inclusive, novos letramentos.

Diante dos resultados obtidos nas pesquisas de Creighton e Szymkowiak (2014) e Knaul (2015), pode-se inferir que o conteúdo, as estratégias e as mediações pedagógicas influenciam o comportamento das crianças, beneficiando a interação social na sala de aula.

A partir disso, reforça-se que os jogos, tanto digitais como analógicos, podem oferecer valiosas contribuições aos processos de ensino e aprendizagem, agregando o lúdico e a diversão à apropriação de conhecimento e ao desenvolvimento de habilidades 
e atitudes. Assim, destaca-se que o uso no contexto escolar potencializa essas contribuições, pois a partir da combinação entre a mediação pedagógica e a possiblidade de interação social, as experiências vivenciadas são enriquecidas com o uso da tecnologia. Por isso, cabe investigar e analisar melhor os usos e possibilidades de integração dos jogos digitais às práticas pedagógicas.

\section{Metodologia}

O estudo realizado caracteriza-se como um estudo de campo (GIL, 1999) de abordagem mista, pautando-se na observação por meio da descrição narrativa e da contagem de frequência por amostragem de tempo (BENTZEN, 2012) para descrever comportamentos das crianças na interação com os jogos analógicos e digitais em sala de aula presencial, visando proceder a comparação e análise.

Participaram desta pesquisa 25 estudantes do terceiro ano dos Anos Iniciais de uma escola pública federal do município de Florianópolis. Destes, 11 eram meninas e 12 eram meninos, com idades entre oito e nove anos de idade.

Os procedimentos pautaram-se na proposição de quatro intervenções com a turma, prevendo o uso de dois jogos um com base no Material Dourado e outro com foco no Tangram. Cada jogo, utilizado nos dois formatos, procurou ter maior aproximação entre as dinâmicas e regras. Assim, para cada jogo foram dois dias de intervenção, sendo o primeiro focado no jogo analógico e o segundo, no jogo digital.

Os jogos pautados no Material Dourado envolveram a realização de cálculos com apoio do uso desse material. Na proposta com a sua versão analógica, os desafios foram entregues em folhas impressas, incluindo duas fases. Na primeira, era preciso indicar a quantidade de peças para somar os valores e, na segunda, havia duas trilhas a serem preenchidas com os valores resultantes, conforme a figura 1. 
Figura 1: Primeira e segunda fase do jogo do material dourado analógico

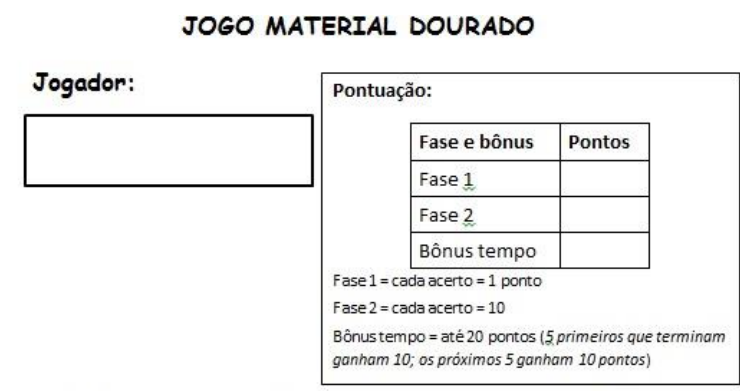

FASE 1: Quantas peças é preciso para somar o número indicado?

\begin{tabular}{|c|c|c|c|c|}
\hline Número & Milhar & Centena & $\begin{array}{c}\text { Dezena } \\
\text { 首 }\end{array}$ & Unidade \\
\hline 86 & & & & \\
\hline 532 & & & & \\
\hline 785 & & & & \\
\hline
\end{tabular}

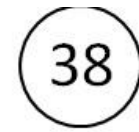

$+$
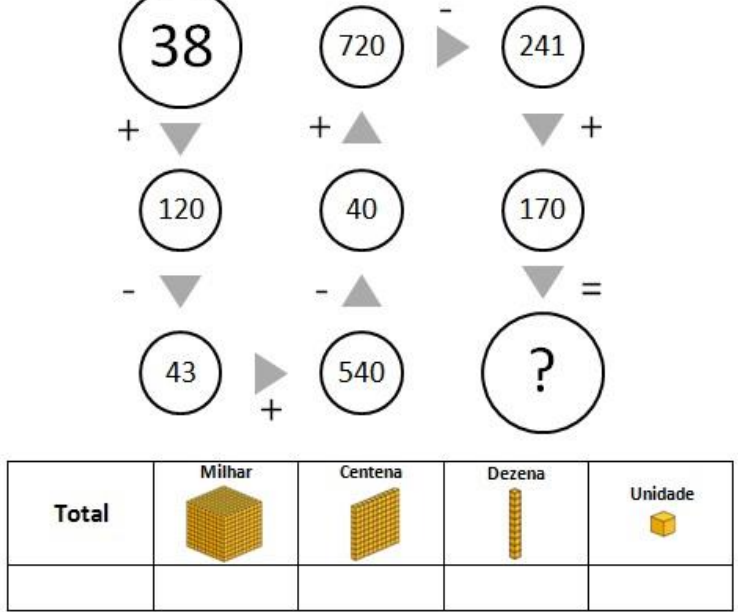

Fonte: Elaboração das autoras, 2017.

O jogo Blocos da Escola do Cérebro foi utilizado como jogo do Material Dourado digital. A Escola do Cérebro é um sistema que "integra jogos cognitivos a uma base de dados que permite tanto o exercício das habilidades cognitivas como o acompanhamento e a orientação sobre o desempenho e características cognitivas dos jogadores" (RAMOS, 2014, p. 72). No primeiro nível do jogo, é preciso arrastar ou clicar nas peças do Material Dourado para compor o número que aparece. No nível seguinte, parte-se do valor anterior para chegar no novo número, sendo necessário excluir ou incluir peças, conforme demonstra a figura 2 a seguir. 
Figura 2: Tela do Jogo Blocos (Material Dourado)

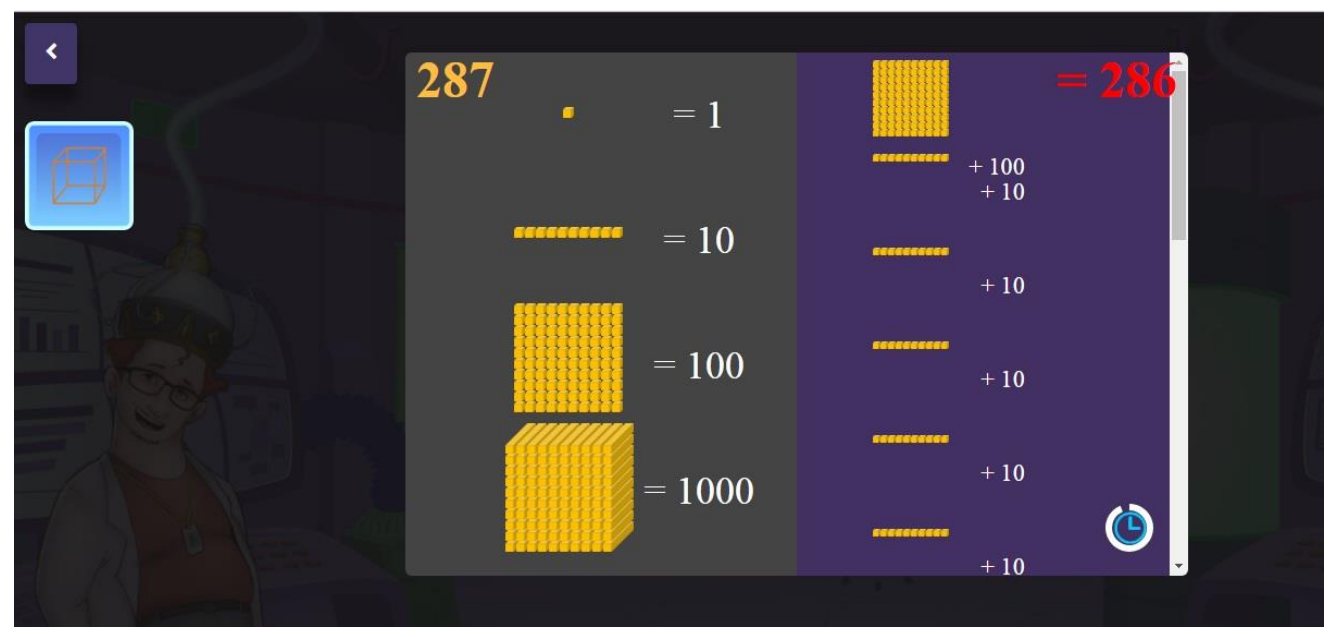

Fonte: Escola do Cérebro, 2017.

Na aplicação do jogo do Tangram analógico foram entregues às crianças quatro formas impressas para que elas montassem as figuras usando as peças (FIGURA 3).

Figura 3: Crianças jogando o Tangram analógico

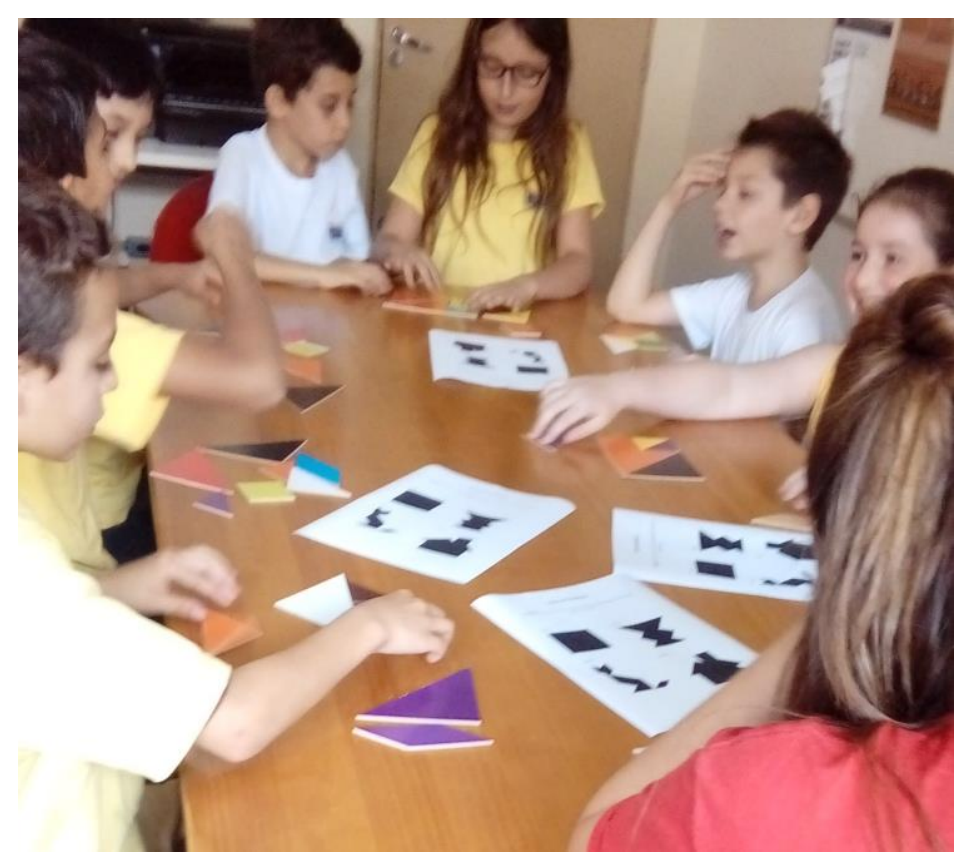

Fonte: Registro da Intervenção, 2017. 
O jogo digital do Tangram apresentava a sombra das imagens para que o jogador arrastasse as peças para compor a figura. No nível fácil, a imagem já é composta por duas peças colocadas, conforme figura 4, a seguir.

Figura 4: Tela do Jogo do Tangram digital

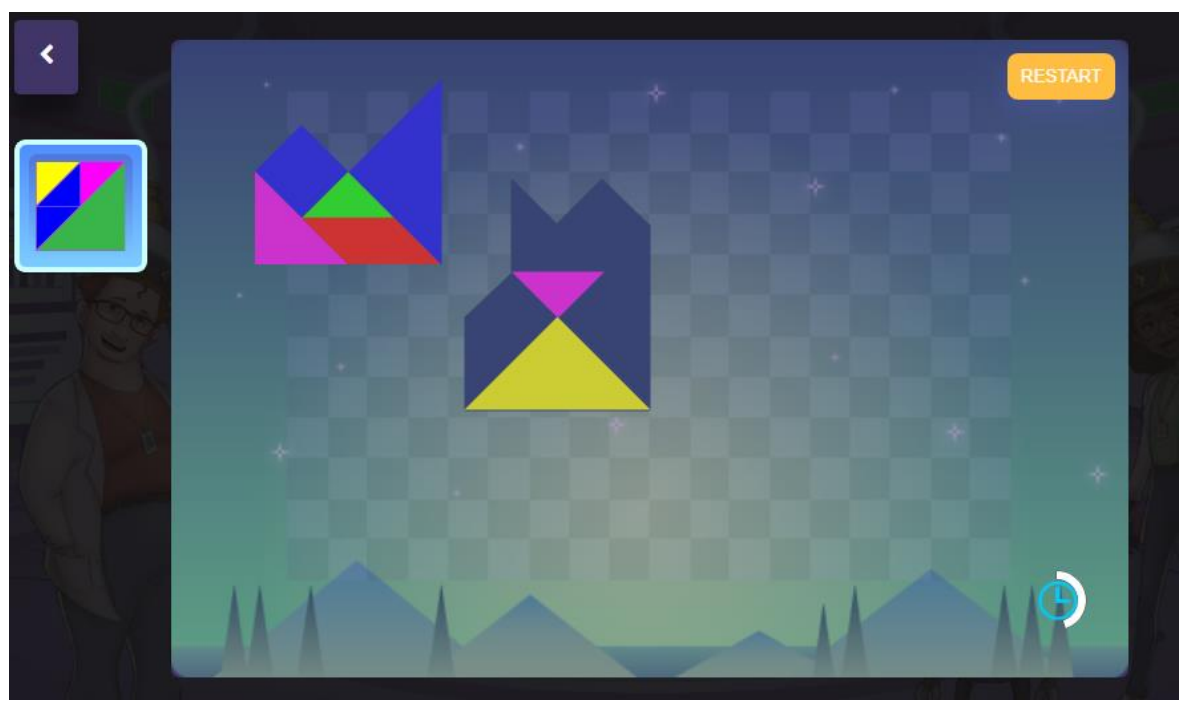

Fonte: Escola do Cérebro, 2017.

Um dos procedimentos de coleta orientou-se pela observação e descrição narrativa, a qual focava na descrição do espaço físico, nos recursos didáticos utilizados e, principalmente, na interação dos participantes com os colegas, professora e com os jogos, em seu ambiente natural enquanto as atividades eram desenvolvidas. As pesquisadoras não participavam das interações em sala de aula presencial, apenas observavam e registravam cada detalhe, conforme previsto anteriormente.

A descrição narrativa é um método formal de registro do comportamento, o qual procura descrever detalhadamente os comportamentos observados, fazendo o registro enquanto os comportamentos ocorrem, considerando critérios pré-determinados (BETZEN, 2012). As descrições narrativas da pesquisa foram realizadas individualmente por cada pesquisador e por intervenção. A pesquisa contou com a participação de quatro observadores por intervenção que ficaram responsáveis por fazer o registro por mesa, conforme pode-se observar na figura 5. Cada intervenção foi registrada em um documento de texto on-line, instrumento utilizado para registo e compartilhamento dos 
dados coletados entre os pesquisadores envolvidos, para que todos pudessem ter acesso às informações e, a partir deles, pudessem definir as categorias para a análise de frequência.

Figura 5: Esquema da planta da sala e informações sobre a observação.

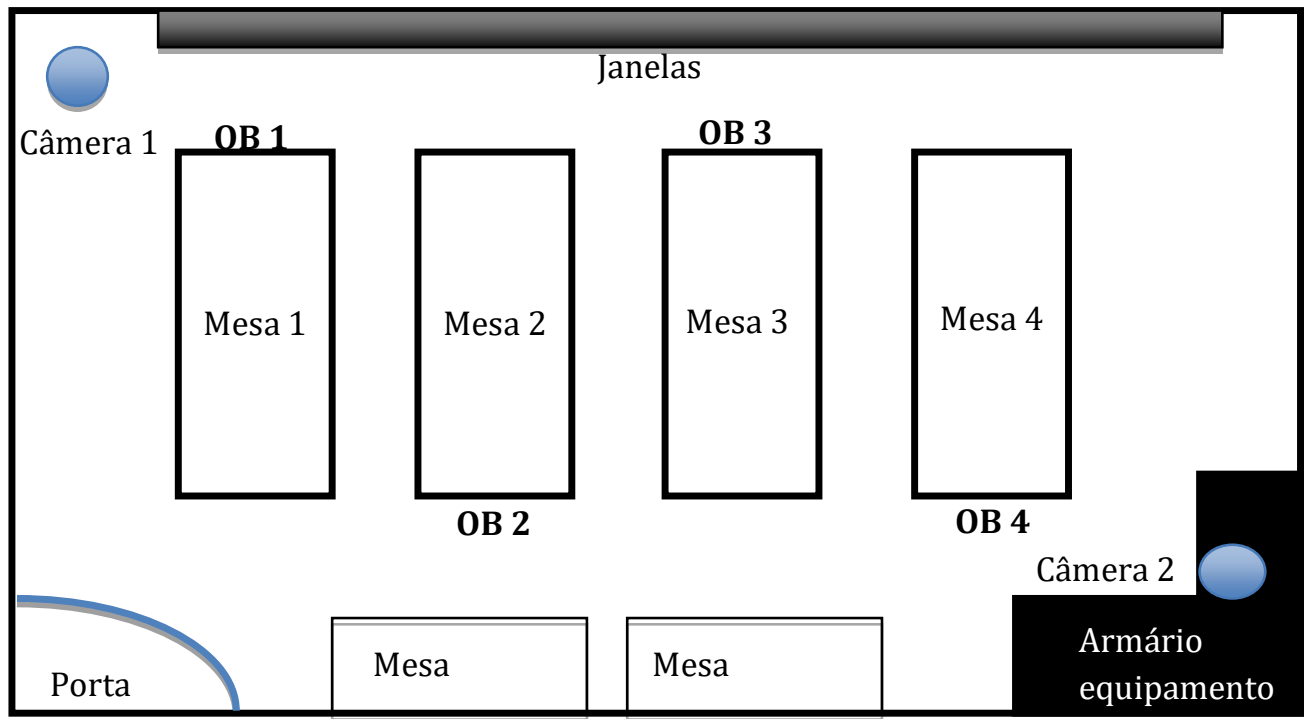

Fonte: Elaboração das autoras, 2017.

Além disso, as intervenções foram filmadas e posteriormente analisadas com base no registro da contagem da frequência de comportamentos. De acordo com Betzen (2012), a contagem da frequência pode estabelecer referências em relação à modificação de comportamentos e, no contexto da pesquisa, auxiliou a verificar se ocorreram modificações em relação aos comportamentos indicativos das categorias de análise quando se utilizaram diferentes jogos e formatos.

A contagem da frequência seguiu o procedimento de amostragem de tempo (BETZEN, 2012), pois foram contabilizados os primeiros 15 minutos de cada intervenção após as crianças terem iniciado a interação com os jogos propostos, ou seja, não se considerou o tempo de explicação e organização da atividade na observação.

Considerando que cada intervenção teve duração de aproximadamente 30 minutos, por meio de observação descritiva em diário de bordo e com o auxílio da filmagem em vídeo, foi possível identificar os comportamentos e suas frequências durante o uso das tecnologias na atividade com jogos. 
As categorias para a análise de frequência, tanto para os jogos analógicos quanto para os digitais, foram, então, definidas a partir de discussões provenientes da descrição narrativa da observação do comportamento dos alunos mediante a interação com os jogos. (CRESWELL, 2010).

A primeira categoria refere-se à atenção que está relacionada à concentração da atividade mental em uma atividade, ignorando informações não relevantes (MATLIN, 2003; STERNBERG, 2008). No jogo, relaciona-se a atenção com a imersão que supõe o forte envolvimento do jogador a ponto de não perceber o tempo passar, e certo desligamento do mundo (PREECE; ROGERS; SHARP, 2005).

De outro modo, a categoria interação social remete ao envolvimento com outras pessoas e ao sentimento de compartilhamento (SAVI et al., 2010). Pode ser associada a comportamentos colaborativos, os quais se pautam na comunicação, no compartilhamento de informações e na ação conjunta para aprender ou tentar aprender algo junto (ROSATELLI et al., 2003)

Por fim, a categoria diversão está fortemente vinculada à interação com os jogos (CAILLOIS, 1990; HUIZINGA, 2010) e remete a comportamentos que expressam a alegria e o prazer (PEREIRA, 2005). A descrição das três categorias pode ser observada no quadro 1 a seguir:

Quadro 1: Descrição das categorias de análise

\begin{tabular}{|c|l|}
\hline CATEGORIA & \multicolumn{1}{c|}{ DESCRIÇÃO DA CATEGORIA } \\
\hline Atenção & Dispersa da atividade, realizando outra atividade diferente da proposta. \\
\hline Interação Social & Professor (a) presta auxílio e oferece dicas para um aluno(a) sobre o jogo. \\
\cline { 2 - 3 } & Presta auxílio e oferece dicas para um colega sobre o jogo. \\
\hline Diversão & Demonstra alegria, expressando-se corporalmente ou sorrindo. \\
\hline
\end{tabular}

Fonte: Elaboração das autoras, 2017. 
Após definição das categorias, foi realizada a análise da frequência de cada uma delas, cujos resultados são apresentados a seguir.

\section{Resultados e discussão}

A partir das intervenções com o uso de jogos analógicos e digitais do Material Dourado (Blocos, denominação da versão digital) e do Tangram, que ocorreram em dias alternados, para análise da motivação das crianças, do modo como se desenvolveram as interações sociais nesses momentos e da diversão incutida com cada tipo de jogo, percebemos algumas mudanças no comportamento das crianças. Destaca-se que tanto as técnicas e regras de cada jogo, como o fato de serem analógicos ou digitais, provocaram mudanças nos comportamentos das crianças, constituindo-se como variáveis que podem ter colaborado na modificação em suas formas de agir nesses momentos.

É importante ressaltar que o formato dos jogos, em suas versões digital e analógico, contribuiu nessa alteração de comportamento das crianças durante o uso, considerando que o digital possui feedbacks automatizados e uma estética visual diferenciada em relação ao analógico, que se trata de um jogo físico que necessita ser manipulado e montado pela criança. Nos jogos digitais temos muitos estímulos, cores e movimentos, que nos capturam facilmente, e, ainda, temos feedbacks constantes e imediatos (PRENSKY, 2012).

Na proposição com a utilização do Material Dourado, no qual as crianças tinham que resolver alguns cálculos propostos numa folha, a partir da utilização do jogo físico, em comparação a um segundo momento em que a mesma atividade foi proposta, mas com a mediação do jogo digital Blocos, percebemos que na inserção do jogo digital as crianças se mostraram mais alegres, expressando isso verbalmente, conforme os relatos das observações do campo, descritos a seguir:

Criança 1: Dá para vir aqui no recreio? Ciclano disse que vai colocar o jogo no tablet dele em casa.

Criança 2: Eu to suando e nem to fazendo atividade física.

Criança 3: Nossa! O avançado é muito legal!

Criança 4: Eu preciso treinar bastante para chegar até 100 antes de eu ir pro avançado.

(Relato das observações do dia 20/09/2017) 
A diversão está fortemente associada à prática com jogos, mesmo nas concepções mais clássicas como de Huizinga (2010) e Caillois (1990), eles são caracterizados como uma atividade lúdica. O lúdico relaciona-se com a ideia de experiência plena de envolvimento, atenção e entrega total (LUCKESI, 2005), ao mesmo tempo em que envolve a alegria e o prazer que podem ser experienciados individual ou coletivamente (PEREIRA, 2005).

Nesse sentido, as falas transcritas apontam para as manifestações de diversão no jogo digital, já que em relação ao analógico não constatamos muitas manifestações. No jogo digital do Tangram, Blocos, um dos aspectos que contribuiu com a diversão foi o fato de se ter um tempo delimitado para realizar os cálculos, diferentemente do jogo analógico em que esse tempo não era controlado. No digital, o próprio sistema. ao findar o tempo. encerra a jogada automaticamente, sem qualquer possibilidade de negociação. A regra relacionada ao tempo no jogo do Bloco caracteriza-se como uma diferença entre o jogo digital e analógico, como pontua Jull (2003), ao indicar que no analógico tem-se a possibilidade de negociar as regras e que, de modo geral, no digital as regras já estão estabelecidas.

Além das expressões verbais das crianças, notamos alguns comportamentos que nos indicaram esse dado ao jogar o Blocos:

A outra menina que estava sentada ao lado comemora sozinha que conseguiu passar uma fase, e quando vê o desafio da nova fase ela se abana com as mãos e demonstra-se ansiosa pra continuar. (Criança observada na mesa 1)

Em outra mesa observei que os meninos competiam, mas de modo colaborativo, ficando contentes com o acerto do outro e realizando toquinho em sinal de contentamento e apoio. Um deles fala: - Acertei! Vamos para o avançado!? (Crianças observadas na mesa 2)

Um menino joga o nível avançado. Ao acertar bate palmas, sorri e em poucos instantes volta a realizar o jogo. (Crianças observadas na mesa 2) Uma das meninas chama a professora para mostrar que ela não errou nada até agora, e sorri. (Criança observada na mesa 3).

(Relato das observações do dia 20/09/2017) 
Além do relato descritivo, por meio da análise das frequências de comportamentos das crianças identificadas por meio da filmagem, esses dados validam de maneira objetiva as observações descritas, conforme pode ser verificado no gráfico 1, a seguir.

Gráfico 1: Frequência de comportamentos com o jogo digital e analógico do Material Dourado

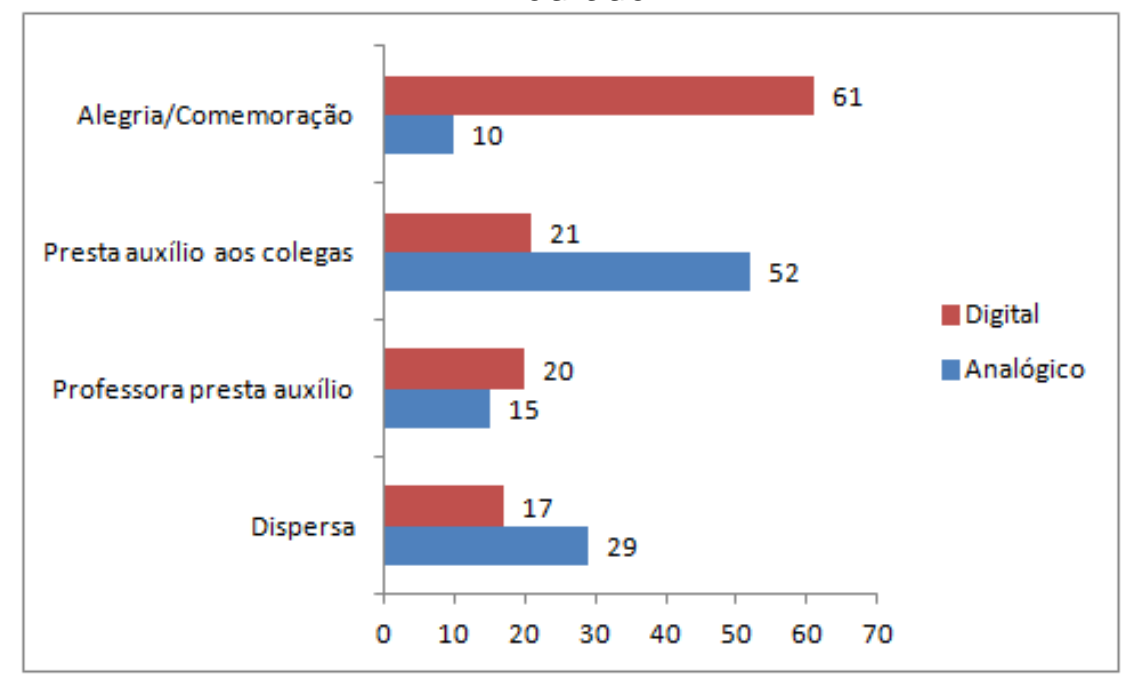

Fonte: Elaboração das autoras, 2017.

No gráfico 1, destaca-se a diferença no registro de comportamento indicativo de alegria e comemoração em que se contabilizou uma frequência correspondente a 85,95\% no jogo digital, revelando ainda que o alunos dispersaram menos nesse tipo de jogo $(36,96 \%)$ e que necessitaram mais do auxílio da professor, o que contabilizou $57,14 \%$ da frequência registrada.

Por outro lado, no jogo analógico, as crianças prestaram mais auxílio aos colegas, somando a frequência que correspondeu a $21,23 \%$ dos registros, demonstrando que as crianças colaboraram e interagiram mais nesse tipo de jogo. A seguir, destacamos alguns trechos dos registros feitos da observação durante o uso do jogo analógico do Material Dourado:

Com a não compreensão da atividade por sua colega, uma menina fala: Eu entendi! Faz esse daqui mais esse aqui! Como alguns não tinham entendido uma parte do jogo proposto pedem auxílio a professora. (Crianças observadas na mesa 1 ) 
Duas alunas se ajudam no entendimento da atividade e dois meninos se concentram e fazem tudo juntos. (Crianças observadas na mesa 2)

Em todos os momentos em que observei os meninos via tranquilidade, trabalho coletivo, colaboração e algumas conversas entre eles. Para eles, ficou visível o envolvimento na atividade proposta, que ocorreu com pouco auxílio do material dourado. (Crianças observadas na mesa 2 )

"Como se cria um cubo?" Essa foi a pergunta de uma criança ao se deparar com um número que necessitava do milhar, mas não tinha o bloco no material. Ele então começou a pegar várias centenas. Outra criança começa a ajudá-lo na conta e outro pega mais centenas. Eles conseguem montar um cubo. (Crianças observadas na mesa 2)

Enquanto uns olhavam, lendo as atividades na folha, outros já perguntavam aos colegas: Criança 1: - É só pra fazer três, então? Criança 2: - Olha o que eu já fiz. Outra questiona o colega ao lado se é pra fazer de tal forma, e o colega ajuda dizendo o que entendeu. Percebo uma criança lendo a folha da outra para entender o que é pra fazer, e nisso um menino conta em voz alta mostrando como se soma/subtrai a conta, e os colegas da mesma mesa prestam atenção. (Crianças observadas na mesa 3)

As meninas que estavam sentadas uma ao lado da outra conversam: - Vou ter que somar todas é isso? E a outra responde: - É! (Crianças observadas na mesa 3)

(Relato das observações do dia 13/09/2017)

Essa maior interação durante o uso do jogo analógico pode se justificar devido ao ambiente do jogo digital apresentar mais feedbacks instantaneamente, além de conter um tempo que limitava a ação da criança no jogo, exigindo uma maior concentração e imersão para realizar a atividade proposta, e assim fazendo com que a criança se individualizasse na sua realização. Esse aspecto reforça a característica de imersão presente no jogo digital, que pode ser relacionada à atenção direcionada para a interação com o jogo, por seus desafios, ações e feedbacks ao ponto de gerar a experiência de fluxo (CSIKSZENTMIHAL, 1991). Essa experiência contribui com a manutenção da atenção, o que se contrapõe à dispersão, e indica a disposição do jogador para jogar (RAMOS; MARTINS, 2018).

Em relação à proposição dos jogos do Tangram, diferentemente do jogo do Material Dourado, as crianças demonstraram uma frequência maior de comportamentos indicativos de alegria e comemoração, o que correspondeu a 63,04\% dos registros feitos nessa categoria. Assim, podemos inferir que não é apenas o fato de ser analógico ou 
digital que garante a diversão, mas a técnica, as regras e os desafios dos jogos também são determinantes para a experiência vivida no jogo.

Destaca-se a importância da mecânica do jogo, pois ela engloba as ações que o jogador executa no jogo, incluindo os desafios, as suas recompensas, a curva de aprendizagem, os esquemas de controle e as ações possíveis ao jogador (CHANDLER, 2012), sendo a combinação dessas características que influencia o modo como ele experimenta a diversão. Entretanto, cabe ressaltar que é difícil associar a ideia de jogo diretamente ligado à diversão, pois o próprio conceito pode ser entendido sob diversas categorias e, ainda, possui aspectos subjetivos; algo pode ser inicialmente divertido e depois de várias repetições torna-se entediante, ou ainda o que é divertido para alguém pode não ser para outra pessoa (ROGERS, 2012).

Ao analisar a frequência obtida na prestação de auxílio aos colegas no Tangram digital, temos uma incidência maior do registro de frequência dessa categoria, o que correspondeu a 62,07\%, reforçando que a interação com o digital não necessariamente individualiza ou possibilita maior colaboração entre as crianças, pois depende de diferentes variáveis. Esse indicativo pode estar ligado ao modo como se desenvolveram as interações sociais durante o uso dessa versão do jogo e a necessidade de compartilhamento, conforme podemos visualizar na transcrição a seguir:

\begin{abstract}
Assim que um menino da mesa termina muito contente de fazer o quadro ele diz: "- Quem quer que eu faça o quadrado para você?"

A professora também monta o quadrado e todos vão olhar. Um aluno diz animado: "- Olha, a profe conseguiu fazer de cabeça para cima. Como você conseguiu fazer o quadrado profe?” Ela responde: “- Tentando!". Sempre que conseguiam montar a imagem com o Tangram as crianças batiam palmas, algumas vezes contando para os/as colegas da mesa ao lado.
\end{abstract}

(Relato das observações do dia 27/09/2017)

Um dado interessante é que as interações sociais associadas à colaboração entre as próprias crianças e à solicitação de ajuda da professora se fez mais presente na versão digital do Tangram, conforme podemos visualizar no gráfico 2 a seguir. 
Gráfico 2: Frequência de comportamentos com o jogo digital e analógico do Tangram

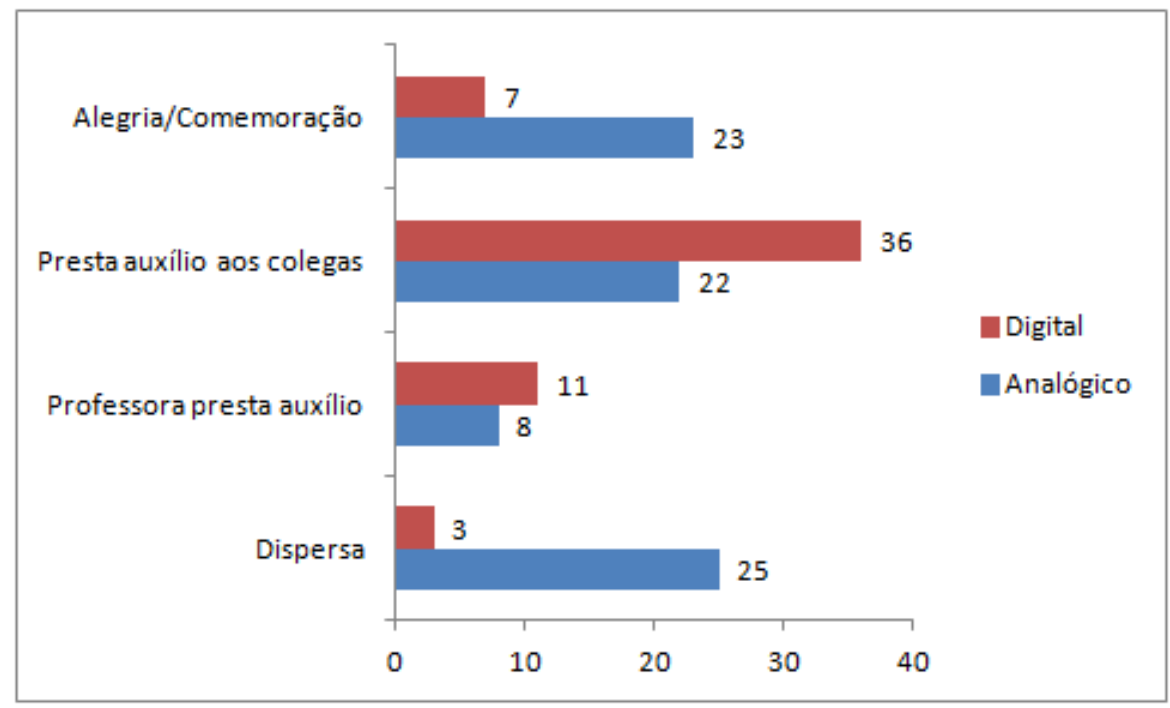

Fonte: Elaboração das autoras, 2017.

Esse maior número de interações em auxílios colaborativos pode estar relacionado à estrutura, formato e conteúdo do jogo digital, que oferecia maior pontuação a quem cumprisse a missão com menos movimentação de peças, cumprindo os 60 segundos para montagem de cada figura, o que interferiu no nível do desafio resultante, promovendo uma maior atenção e imersão das crianças nesse jogo. Embora, tenha resultado numa menor representação de alegria e comemoração das crianças.

Quando os desafios não estão adequados ao nível do jogador, podemos ter maior dispersão. De acordo com Prensky (2012), os desafios precisam estar o mais alinhado possível à capacidade de resolução do jogador, para que possa resultar em um prazer. Em consequência, essa estrutura apresentou um maior nível de dificuldade na sua realização, demandando das crianças maior compreensão sobre a atividade, o que ocasionou em uma maior solicitação de ajuda aos colegas (FIGURA 6). 
Figura 6: Crianças jogando o Tangram digital

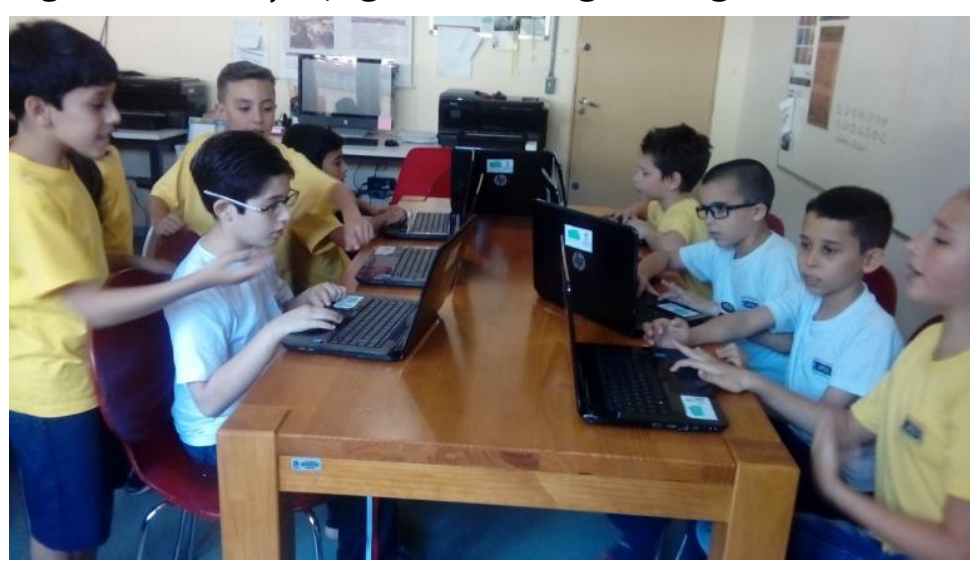

Fonte: Registro da Intervenção, 2017.

Ao analisar o quantitativo da frequência de comportamentos das crianças em relação às versões digital e analógica dos dois jogos, conforme podemos visualizar no gráfico 3, a seguir, pode-se observar que os jogos digitais foram experimentados como mais divertidos, com base na frequência dos registros de comportamentos indicativos de alegria e comemoração, o que também gerou menor frequência de comportamentos indicativos de dispersão nas crianças.

Gráfico 3: Frequência de comportamentos nos jogos em suas versões digitais e analógicas

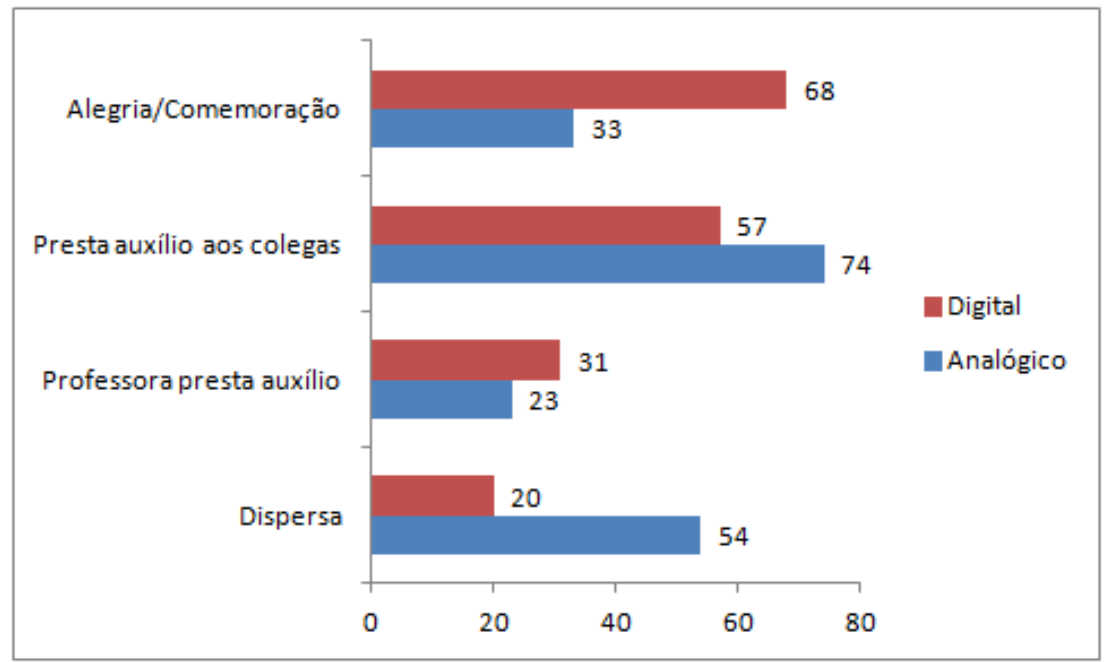

Fonte: Elaboração das autoras, 2017. 
A diversão é fortemente associada às experiências com jogos digitais. Essa diversão, relacionada à satisfação, à alegria e ao prazer, induz o jogador a um estado de espírito distenso e até mais receptivo para a aprendizagem (PRENSKY, 2012). Diante disso, Quinn (2005) destaca que a diversão no jogo está relacionada ao envolvimento do jogador com a história que contextualiza a necessidade de agir baseada em desafio.

Já nos jogos analógicos, observou-se maior prestação de auxílio aos colegas, provavelmente por termos menor controle sobre o tempo e maior dispersão, facilitando que pudessem dividir a atenção entre o jogo e a interação social com os colegas.

De acordo com Annetta (2008), o uso dos jogos digitais na educação dessa nova geração tende a criar um maior envolvimento e experiências de aprendizagem mais motivadoras, proporcionando curiosidade e diversão. Diante disso, podemos considerar que devido à estrutura dos jogos digitais demandarem uma maior atenção e concentração das crianças em relação ao tempo de cada fase e feedbacks, isso fez com que elas ficassem mais entretidas e interagissem menos umas com as outras durante o uso, o que não significa que elas aprenderam menos ou mais com ambas as versões, pois cada uma delas contou com as suas particularidades.

Por fim, consideramos que no desenvolvimento das proposições com os jogos, muitas variáveis podem ter influenciado nos níveis de motivação/dispersão e diversão das crianças nas suas interações sociais. Desde a tecnologia usada como o jogo físico, tablet e notebook, até a estrutura de cada um dos jogos em suas diferentes versões que incutiram níveis de dificuldade distintos gerando, assim, diferentes comportamentos nas crianças.

\section{Considerações finais}

Os jogos constituem-se como experiências diferenciadas que envolvem regras, desafios e diversão. As características apresentam-se em diferentes combinações, intensidades e formas, criando um universo amplo e diverso de tipos e modalidades. No formato desse trabalho, destacaram-se os jogos digitais e analógicos que apresentam características distintas fortemente vinculadas à tecnologia e ao modo como o jogo se apresenta. 
Nos jogos analógicos, as regras podem ser negociadas, não tendo um controle rígido das ações e tempo. Essa maior flexibilidade e possibilidade de construção/adaptação podem favorecer maior interação social quando temos seu uso em contextos como o da sala de aula.

O jogo digital apresenta outras características como interatividade e o feedback imediato que tende a envolver o jogador, tornando-o mais focado na experiência com o jogo, o que tendeu a diminuir a interação social, mas gerou maior diversão.

Além disso, observou-se que o tipo de jogo também influencia fortemente as experiências dos jogadores, já que pode favorecer mais a diversão ou a colaboração, podendo envolver mais ou menos o jogador pois a depender do tipo, de seus desafios e regras, observam-se mudanças no seu comportamento.

Assim, não se pode pensar em uma regra geral que indique o tipo de experiência resultante, tomando como critério apenas o formato do jogo, se digital ou analógico; torna-se fundamental analisar e considerar o próprio jogo. Apesar de identificarem-se algumas tendências, é preciso considerar um contexto mais amplo.

Salienta-se que a partir deste estudo, muitas questões surgem e poderiam ser mais aprofundadas. No entanto, o estudo propôs uma primeira aproximação com o universo dos jogos e seus formatos, destacando os comportamentos sociais. Assim, várias indagações emergem dessa aproximação: quais características dos jogos fomentam maior colaboração entre as crianças? Por que a diversão é mais fortemente experimentada nos jogos digitais? Como podemos transpor as características dos jogos que convidam ao maior envolvimento e foco do jogador para os contextos de aprendizagem? quais são as relações entre a atenção e a diversão experimentada na interação com os jogos? 


\section{Referências}

ANNETTA, Leonard A. Video games in education: why they should be used and how they are being used. Theory Into Practice, Ohio, v.47, n. 3, p. 229-239, 2008. DOI:

$10.1080 / 00405840802153940$.

BENTZEN, Warren R. Guia para observação e registro do comportamento infantil. São Paulo: Cengage Learning, 2012.

BROUGÈRE, Gilles. Jogo e educação. Porto Alegre: Artes Médicas, 1998.

CAILLOIS, Roger. Os jogos e os homens: a máscara e a vertigem. Lisboa: Cotovia, 1990.

CHANDLER, Heather M. Manual de produção de jogos digitais. 2. ed. Porto Alegre: Bookman Editora, 2012.

CONNOLLY, Thomas M. et al. A systematic literature review of empirical evidence on computer games and serious games. Computers \& Education, [S.I.], v. 59, n. 2, p. 661-686, 2012.

CREIGHTON, Susan; SZYMKOWIAK, Andrea. The effects of cooperative and competitive games on classroom interaction frequencies. Procedia-Social and Behavioral Sciences, [S.I.], v. 140, p. 155-163, 2014.

CRESWELL, John W. Projeto de pesquisa: métodos qualitativos, quantitativos e mistos. 3 . ed. Porto Alegre: Artmed, 2010.

CSIKSZENTMIHALYI, Mihaly. Flow: the psychology of optimal experience. New York: Harper Perennial, 1991.

CUNSKA, Aija; SAVICKA, Inga. Use of ICT teaching-learning methods make school math Blossom. Procedia - Social and Behavioral Sciences, [S.I.], v. 69, n. 24, p. 1481-1488, dez. 2012.

GARCIA, Ivan; PACHECO Carla. A constructivist computational platform to support mathematics education in elementary school. Computers \& Education, [S.I.], v. 66, p. 2539, 2013.

GEE, James P. Bons video games e boa aprendizagem. Perspectiva, Florianópolis, v. 27, n. 1, p. 167-178, 2009.

GIL, Antonio C. Métodos e técnicas de pesquisa social. 5.ed. São Paulo: Atlas, 1999.

HUIZINGA, Johan. Homo Ludens: o jogo como elemento da cultura. 6. ed. São Paulo: Perspectiva, 2010. 
JUUL, Jesper. The game, the player, the word: looking for a heart of gameness. In:

COPIER, Marinka; RAESSENS, Joost (ed.). Digital games research conference proceeding. Utrecht: Utrecht University, 2003. p. 30-45. Disponível em:

http://www.jesperjuul.net/text/gameplayerworld/. Acesso em: 24 out. 2016.

KISHIMOTO, Tizuko M. et al. Jogo, brinquedo, brincadeira e a educação. São Paulo: Cortez, 1999.

KISHIMOTO, Tizuko M. et al. Jogo, brinquedo, brincadeira e a educação. São Paulo: Cortez, 1999.

KISHIMOTO, Tizuko M. O jogo e a educação infantil. São Paulo: Pioneira, 2002.

KNAUL, Ana Paula. Novos letramentos na escola: uma análise da integração do tablet às práticas pedagógicas no Ensino Fundamental. 2015. Dissertação (Mestrado em Educação) - Programa de Pós-Graduação em Educação, Universidade Federal de Santa Catarina, Florianópolis, 2015.

LI, Ming-Chaun; TSAI, Chin-Chung. Game-based learning in science education: a review of relevant research. Journal of Science Education and Technology, [S.I.], v. 22, n. 6, p. 877$898,2013$.

LUCKESI, Cipriano Carlos. Ludicidade e atividades lúdicas. Salvador, 2005. Disponível em: http://www.luckesi.com.br/ Acesso em: 03 maio 2015.

MAHMOUDI, Hojjat et al. The effect of computer games on speed, attention and consistency of learning mathematics among students. Chicago, v. 20, p. 419-424, set. 2014. Disponível em:

https://www.sciencedirect.com/science/article/pii/S1877042815005285. Acesso em: 12 junho 2016.

MARTINOVIC, Dragana et al. Computer games that exercise cognitive skills: what makes them engaging for children? Computers in Human Behavior, [S.I.], v. 60, p. 451-452, 2016.

MATLIN, Margarete. Psicologia cognitiva. 5. ed. Rio de Janeiro: LTC, 2003.

MRECH, Leny. M. A criança e o computador: novas formas de pensar. In: SANTOS, Santa Marli P. dos. (org.). Brinquedoteca: o lúdico em diferentes contextos. Petrópolis: editora, 1997. p. 62-80.

MURCIA, Juan A. Aprendizagem através do jogo. Porto Alegre: Artmed, 2005.

PEREIRA, Lucia Helena Pena. Bioexpressão: a caminho de uma educação lúdica para a formação de educadores. 2005. 388p. Tese (Doutorado em Educação) - Programa de PósGraduação em Educação, Faculdade de Educação, Universidade Federal da Bahia, Salvador, 2005. 
STANISAVLJEVIĆ-PETROVIĆ, Zorica; STANKOVIĆ, Zoran; JEVTIĆ, Bisera. Implementation of educational software in classrooms: pupils' perspective. Procedia - Social and Behavioral Sciences, [S.I.], v.186, p. 549-559, 2015.

PREECE, Jenny; ROGERS, Yvonne; SHARP, Helen. Design de Interação homemcomputador. Porto Alegre: Bookman, 2005.

PRENSKY, Marc. Aprendizagem baseada em jogos digitais. São Paulo: Ed. Senac São Paulo, 2012.

QUINN, Clark N. Engaging learning: designing e-learning simulation games. New Jersey: John Wiley \& Sons, 2005.

RAMOS, Daniela Karine. Cognoteca: uma alternativa para o exercício de habilidades cognitivas, emocionais e sociais no contexto escolar. Revista da FAEEBA - Educação e Contemporaneidade, Salvador, v. 23, n. 41, p. 63-75, 2014.

RAMOS, Daniela Karine; MARTINS, Patrícia Nunes. Jogos digitais na educação a distância: contribuições do design de games à aprendizagem. Revista EducaOnline, Rio de Janeiro, v. 12, n. 2, p. 124-140, 2018.

REYNOLDS-BLANKENSHIP, Tara Lynn. An action research study investigating children's use of an iPad during free play in a kindergarten classroom: an exploration of teaching pedagogy and children's learning, social interactions, and digital literacy. Tese (Doctorate in Philosophy) - Texas Woman's University, Denton, 2013.

ROGERS, Scott. Level UP: um guia para o design de grandes jogos. São Paulo: Blucher, 2012.

ROSATELLI, Marta et al. Ambientes de apoio a aprendizagem cooperativa. In: RAMOS, Edla Maria Faust; ROSATELLI, Marta Costa; WAZLAWICK, Raul Sidney (orgs.). Informática na escola: um olhar multidisciplinar. 1. ed. Fortaleza: Editora da UFC, 2003. v. 1, p. 46-74.

SAKR, Mona; KUCIRKOVA, Natalia. Parent-child moments of meeting in art-making with collage, iPad, tuxpaint and crayons. International Journal of Education \& the Arts, [S.I.], v. 18, n. 2, p. 01-25, 2017.

SANTOS, Wilk O.; SILVA, Alex P.; SILVA JUNIOR, Clovis G. Conquistando com o resto: virtualização de um jogo para o ensino de matemática. In: Simpósio Brasileiro de Informática na Educação-SBIE, 25, 2014. Dourados. Anais [...]. Dourados: UFGD, 2014. p. 317-321.

SAVI, Rafael et al. Proposta de um modelo de avaliação de jogos educacionais. Renote, Porto Alegre, v. 8, n. 3, p. 1-12, 2010.

SCHELL, Jesse. A arte da game design: o livro original. Rio de Janeiro: Elsevier, 2011. 
SCHUYTEMA, Paul. Design de games: uma abordagem prática. São Paulo: Cengage Learning. 2008.

STERNBERG, Robert. Psicologia cognitiva. 4. ed. Porto Alegre: Artmed, 2008.

TALEB, Zahra; AHMADI, Amineh; MUSAVI, Maryam. The effect of m-learning on mathematics learning. Procedia - Social and Behavioral Sciences, [S.I], v.171, p. 83-89, 2015.

TSCHOLL, Michael; LINDGREN, Robb. Empowering digital interactions with real world conversation. TechTrends, [S.I], v. 58, n. 1, p. 56-63, 2014.

UCUS, Sukran. Elementary school teachers' views on game-based learning as a teaching method. Procedia - Social and Behavioral Sciences, [S.I], v. 186, p. 401-440, 2015. 